\title{
Employee Potential Development: Haidilao High Growth Enlightenment
}

\author{
Zhen Liu, Xiaohui Wan \\ School of Management, Shanghai University, Shanghai, China \\ Email: *xiaohuiwan@yeah.net
}

How to cite this paper: Liu, Z. and Wan, X.H. (2019) Employee Potential Development: Haidilao High Growth Enlightenment. Open Journal of Business and Management, 7, 1173-1182. https://doi.org/10.4236/ojbm.2019.73082

Received: April 22, 2019

Accepted: June 30, 2019

Published: July 3, 2019

Copyright $\odot 2019$ by author(s) and Scientific Research Publishing Inc. This work is licensed under the Creative Commons Attribution International License (CC BY 4.0).

http://creativecommons.org/licenses/by/4.0/ (c) (i) Open Access

\begin{abstract}
At the celebration of the 40th anniversary of reform and opening up, the central committee of the communist party of China (CPC) awarded the title of "pioneer of reform" to 100 comrades, including some well-known entrepreneurs and scientists. But among the pioneers who have been commended, there are also representatives of ordinary people who are silently dedicating behind the scenes. These thousands of ordinary people who love their jobs have created brilliant achievements in reform and opening up with diligence, courage and wisdom. Therefore, on the new starting point of the achievements in the past 40 years of reform and opening up, it is especially worthwhile to explore and summarize how to release the value of ordinary people, in order to make more ordinary people achieve extraordinary achievements in the future, and Haidilao is an example of the achievements of ordinary people. This paper takes Haidilao, a well-known catering company, as an example. It briefly analyzes how Haidilao develops the creativity of its employees, and how ordinary people help Haidilao to grow at a high speed and achieve themselves. Haidilao is an example of the achievements of ordinary people. Taking haidilao, a well-known catering enterprise in China, as an example, this paper briefly analyzes how haidilao develops its employees' creativity, and how ordinary people help haidilao grow rapidly and achieve self-accomplishment. Consequently, recommendations for its development and improvement were put forth.
\end{abstract}

\section{Keywords}

Employee Potential, Employee Creativity, Haidilao

\section{Introduction}

In the era of knowledge economy, most entrepreneurs prefer to hire knowledge 
workers; in fact, the source of value is diverse, and no matter what kind of workers, they need to create extraordinary value in essence. In haidilao, these extraordinary values are created by a group of very ordinary employees. In fact, we need to not only focus on the contribution of entrepreneurs, but also see that there are more down-to-earth ordinary people creating important value in the whole process. These people may not yet be bosses or entrepreneurs, or even managers, but they are making important contributions in a downright way, and only when our spotlight is on them will it lead more ordinary people to achieve extraordinary things.

Into the era of knowledge economy, enterprise development needs to rely on talent reserves; how to give full play to people's enthusiasm and creativity, is the primary task of enterprise talent potential; therefore, enterprises need according to different objects in different environments using different method, to excavate the maximum potential of employees, and the key to excavate potential employees is arouse the creativity of employees. With the development of employee creativity, more and more scholars have found that employee creativity is the source of organizational competitiveness. The play of employee creativity can promote organizational innovation and promote the sustainable development of the organization in the fierce competition, because employee creativity can produce novel and useful products and services [1] (Amabile, 1996). Nowadays, one of the key elements to maintain the competitive advantage of an organization is innovation [2] (Liu yun, Shi Jintao, 2010). Only by constantly developing the potential of employees, employees can create new products and services to cope with the changing industry environment and the international competition.

In recent years, researches on the development of employees' potential have been emerging, and many scholars have reviewed and sorted out the research results on the development of employees' creativity, and summarized the current research progress. Moreover, in the existing literature research, a large number of scholars' research results show that the improvement of employees' creativity plays an important role in the practice of enterprise human resource management [3] [4] (Chang et al., 2014; Chiang et al., 2015). Therefore, based on the case study of haidilao, a well-known catering enterprise, this paper discusses the development mode of human resource management for employees' potential, and through the exploration of employees' creativity in different situations, it promotes the continuous innovation of products and services and attracts more consumers. It can be seen that the effective display of employees' creativity is the key to the development of the organization and also the guarantee of the continuous innovation of the organization. This paper combines employee creativity with enterprise management practice, studies and analyzes cases, and puts forward management suggestions, so as to provide references for future research.

\section{Research Review}

The study of creativity began in psychology in the 1950s and developed into the 
field of management. However, up to now, many researchers have studied creativity, and the research results are different, so the definition of creativity has not yet formed a clear understanding. Although scholars to the definition of creativity is unclear, but most scholars base used in the field of organizational behavior, based on the viewpoint of creative results, defines employees' creativity as: staff for the organization's products and services, production process and the method and management pattern with a potential value of the innovative idea [5] (Zhou \& George, 2001). This definition clarifies the definition of employee creativity and enables it to be quantified, so as to evaluate and assess the creation results, which is conducive to the follow-up research of researchers.

Among them, the influencing factors of employee creativity are mainly divided into three categories, that is, individual idiosyncratic factors of employee creativity, situational factors and the interaction between them. Many scholars say that creativity is captured not only by individual traits but also by environmental considerations [6] (Plucker et al., 2004). Meanwhile, Zhou and Hoever (2014) studied the interaction between the individual and the situation on creativity, and the interaction between the factors based on the characteristics of the creative individual and the creative situation on creativity [7].

At present, existing studies have shown that the interaction between individual traits and organizational situational factors can influence the mechanism of employee creativity [8] (Yuan \& Woodman, 2010). More and more scholars, based on the field of organizational behavior, focus on exploring the influence of the interaction between individual characteristics and organizational context on creativity. A large number of research reviews show that interpersonal and task and other situational factors can enhance the play of employees' creativity. Research scholar Kozlowski (1987) proposed that HRM practices in an organization are closely related to each employee and can affect the whole proess of employees' creative thinking and behavior [9]. However, there are few researches on the application of employees' creativity in enterprise management practice.

\section{Research Methods}

\subsection{Composition Theory of Creativity}

Research on employee creativity has been highly valued in the past two decades, and relevant research results have been emerging continuously. The earliest is the componential model of creativity proposed by Amabile (1993), which holds that work motivation, creativity related skills and skills in related fields are the key components of employee creativity [10]. Among them, the internal work motivation plays a key role in the development of creativity, which refers to the individual's internal driving force for the creative work he participates in, including the perception of whether he is interested in and satisfied with his activities. Creativity-related skills mainly refer to the solving strategies and methods of creative problems, including cognitive ability, individual characteristics and risk preference. Domain-related skills refer to the domain-specific knowledge and 
skills of the creative subject. In addition, Amabile (1996) proposed that the three components of the creativity composition theory are also related to the environment [1]. Research scholar Shalley (2004) also proposed that organizational situational factors of creativity include leadership style, organizational atmosphere, task characteristics and other factors [11].

\subsection{Interactive Theory of Creativity}

Woodman, Sawyer and Griffin (1993) put forward the interactive theory of creativity [12]. The theory holds that individual factors and situational factors interact with the exertion of employee creativity, which is influenced by the complex interaction between individual characteristics and organizational situation, and the interaction between individual characteristics and organizational situation has a strong prediction of employee creativity. Most researchers, in the field of histology, use the interaction between individual traits and situational factors to study the mechanism of employees' creativity [8] (Yuan \& Woodman, 2010). In addition, scholars also discussed and studied the influence of the interaction of other factors, such as emotion, leadership behavior and goal orientation, on creative activities. Situational factors include the scope of HRM practices, so the combination of HRM practices and employees' personal factors can effectively affect their creativity. Scholar Chiang et al. (2014) found that information exchange also affects employee creativity [4]. In the practice of enterprise management, studies have found that the influence of employees' work participation on employees' creativity is also influenced by the organizational managers and interpersonal relationships [13] (Isabel Ma \& MaPilar, 2014).

\section{Case Analysis of Haidilao}

In September 2018, haidilao successfully went public, and its initial public offering reached a market value of 100 billion yuan. For China's restaurant industry, which has a low industrial concentration, this is a huge number. However, this huge number is created by a group of ordinary people. Sichuan HaiDiLao catering Co. Ltd. is a large span food private enterprise that gives priority to Sichuan-style hotpot and merges different characteristic hotpot into an organic whole. Since its establishment in 1994, haidilao has grown from a small shop into a leader in the catering industry in only 24 years, and now there are more than 400 directly-managed stores, seven large modern logistics base and a raw material production base. HaiDiLao has become one of the leaders of China's catering industry. Haidilao so fast growth is how to achieve it?

\subsection{Awaken the Potential: To Explore the Value of People Is the Greatest Respect for People}

The core value of haidilao is "hands change destiny", which is also the belief of all employees in haidilao. Zhang yong, founder of haidilao, once said, "haidilao only treats its employees as human beings". This shows that haidilao highly re- 
spects its employees, because all employees in haidilao are ordinary workers who need real respect. Therefore, haidilao always adheres to the concept of "more work, more gain, hands change the fate" to create a fair and just working environment for workers and help them grow up. Haidilao also respects employees, pays attention to their lives and treats them as family members. Although in maslow's hierarchy of needs, the need for respect belongs to the needs of higher levels, when the need for respect is satisfied, people can be full of confidence in themselves, full of enthusiasm for the society, and feel the value of their work and the meaning of life. Haidilao gives respect from the bottom of its heart to every worker, which makes people full of enthusiasm and activates the potential value of workers.

It is the greatest respect for people to deeply explore their intrinsic value. Haidilao always shows the most basic respect to every worker, and fairly treats and evaluates the value created by every worker. Not only to employees as family, attention to each ordinary people can create value, but also to help employees wake up their potential. And the depth of this potential, so that workers in ordinary positions to achieve self-worth.

Haidilao current chief operating officer Yang Lijuan, from a junior high school dropout ordinary girl, into haidilao step by step struggle for the net worth of more than 100 million directors, is haidilao woke up her potential. Haidilao not only in her home in an emergency, prepaid wages to help solve their pressing needs; Haidilao founder Zhang yong is to personally teach Yang Lijuan to record and reflect every day, designated book list let her continue to learn. Haidilao with the power of the supremacy of the only promotion path, also let her through their continuous efforts, only two years from the waiter to become the manager; At the same time, haidilao also dared to employ people, sending the 21-year-old to manage its branches in Xi'an and inspiring her management talent with challenges. And she did not live up to the haidilao to give the trust and support, not only not afraid of provocative customers, but also personally to hand out leaflets to do propaganda, do their best to contribute to the company. At the time of the crisis, let open half a year has been in the loss of Xi'an branch back to life, and won the reputation of the local. It was she who won her dignity with hard work and finally became the leader of the company and realized her self-value.

\subsection{Value Co-Creation: Open the Symbiotic Mode of Ordinary People}

In the Internet information age, independent struggle has been unable to adapt to the requirements of the times, and interactive cooperation can bring more extraordinary value, ordinary people need to symbiosis each other, self-achievement. When ordinary people live together rather than alone, each ordinary person creates great value. As professor Chen Chunhua points out in his book symbiosis, there are four levels of "symbiosis" [14] [15]. One of them is the belief in "symbiosis", which enables people to be self-restrained, neutralize altruism and 
strive for growth. Haidilao and every ordinary people, in the realization of self-worth at the same time, and help others grow, bless each other, together to achieve a remarkable cause.

Most of the employees recruited by haidilao at the beginning of its establishment came from Jianyang, Sichuan province, the hometown of its founder Zhang yong, and haidilao also implemented the recommendation system in recruitment, so most of the employees of haidilao are familiar with their hometown. These people from the same hometown can quickly understand and integrate with each other to form a unified value system. They can not only open the symbiosis mode, but also share the same fate with haidilao, build a community of interests and create value for haidilao. As people who are familiar with each other from the same hometown, it is easier to accept the service concept of haidilao. Every ordinary people by instinct survive and create value, but in haidilao form a whole. Every employee of haidilao knows that his or her fate is closely related to other employees and the development of the enterprise. Therefore, everyone in haidilao has a sense of responsibility for his or her own actions, has consistent behavior choices, reaches common beliefs and values, and forms a common growth model.

\subsection{Process Efficiency: Ensure the Results with the Quality of Work}

Although benefit result is the ultimate goal that the enterprise pursues, but effective process, ability assures the quality of result. Therefore, haidilao cares about people, cares about the value created by ordinary people, and cares about the happiness of employees. Because a happy person and an unhappy person may behave differently at work. But what exactly is happiness? The "happiness" in management science does not mean simple enjoyment or hedonism, but how to make people do things more effectively, because the utility of management is reflected in whether the ordinary can be transformed into excellence. Therefore, from the perspective of management efficiency, there should be a clear standard for happiness: a happy employee should be able to settle down and concentrate on work without being disturbed by various things, otherwise the quality of work will not be guaranteed, and the efficiency of people will have problems.

Nowadays, many enterprises judge employees' efficiency by rigid performance indicators, while haidilao focuses on whether employees can work in peace of mind. Because haidilao knows that only when employees work at ease, their work efficiency and creativity can be guaranteed, which is the essence of staff work assessment: attach importance to the work process, rather than being trapped in the erroneous zone of just blindly assessment results. Therefore, the ultimate goal of haidilao is to make employees settle down to work, whether it is to provide them with accommodation nearby, clean their rooms, send subsidies to their parents, help them fulfill their filial piety, or establish schools for their children. Because only when you concentrate on doing things, you can release your concentration, which makes you more powerful. Only when you are at 
ease, you can be more efficient and feel happy.

Haidilao staff always smile to customers, and is from the heart, sincere smile, so that customers feel haidilao staff cordial and warm [16]. This kind of smiling service is not enforced by haidilao, but the result that haidilao makes employees happy. Haidilao solves the basic life problems of employees, enables them to work with peace of mind, concentrate on work, makes them full of enthusiasm for life, improves their work efficiency and constantly creates value. And it is because of the performance of the staff in the process of work, to ensure that the haidilao high quality service results [17].

\subsection{Belief in Customers: Creating Customer Value Is the Highest Achievement}

Today, many enterprises use a large number of indicators and multiple methods to assess employee performance, but may neglect to focus on customer value to measure employee performance. However, in haidilao, customers are the basis of evaluating the value creation of employees, and all evaluations of employees are centered on customer value. Haidilao pays the most attention to whether employees can create continuous value for customers. As long as employees satisfy customers and create value for customers, they are good employees, because only customer value can represent the real achievements of employees.

Haidilao evaluates the value of customers to motivate employees to pay attention to customers' needs, create useful products and services for customers, meet customers' differentiated needs to the maximum extent, and provide services full of innovation and even beyond customers' expectations. Employees are continuous innovation, launched haidilao differentiated services from other enterprises. In addition to free manicures, free childcare, free fruit snacks, eyeglasses cloths for bespectacled customers, and basic services like rubber bands for ladies who give off hair. Haidilao also recently launched a new clothing "deodorization" service for customers, but also free to customers' mobile phones, bags and other non-washable items to provide anti-bacteria, anti-mite services. Haidilao's continuous innovation comes from its employees' focus on customer value.

When employees have the corresponding values and concepts, they can create more surplus value for the enterprise and promote the sustainable development of the enterprise [18]. Fellow villagers in haidilao are more likely to form like-minded groups, build a harmonious working environment, effectively convey work information, and create extraordinary value. Haidilao has almost no job restrictions, because when there is a job gap in need, whether it is cleaning personnel or security personnel and other positions will help each other in a timely manner, so that customers' needs can be met immediately [17]. This is the unique and spontaneous dedication of haidilao, and also the symbiotic mode of cooperation between haidilao compatriots.

Haidilao's evaluation of employees is always to make customers satisfied. Although haidilao employees at all levels have different career development paths, 
the final evaluation index of each path is to point to customer value. In order to ensure that customers' needs are met in a timely manner, haidilao also introduced an authorization system for employees to give them trust. In haidilao, ordinary employees can give free snacks and snacks to customers, and even have the right to offer discounts and free of charge to customers. Such power is almost non-existent in other catering enterprises, and it is haidilao's trust that fully inspires the creativity of its employees. But this kind of trust and authorization is not excessive, haidilao employees have a card, all their services in the store, need to swipe the card, recorded. Once abuse is discovered, trust and empowerment will not occur again. By means of appropriate delegation of power and reasonable monitoring, it not only meets the respect needs of employees and improves their work enthusiasm, but also enables employees to eliminate all customer complaints in time, so that quality accidents can be solved in time and customers are satisfied.

\section{Research Results}

\subsection{Research Significance}

Employee creativity is particularly important for HRM practices, and the full development of employee potential is conducive to the development and progress of the organization. Employee creativity is not only related to individual characteristics of employees, but also closely related to organizational context. Therefore, in an organization, matching work tasks according to different characteristics of employees can better improve work performance. Through case study analysis of haidilao, the staff has a large influence on the development potential of mining. Haidilao by developing staffs creativity, implements and maintains the innovation of the enterprise competitive advantage, and wins over rivals. Through respect for every employee, let the staff give full play to its own value, continue to awaken the potential employees, share values, fully motivate employees, let employees self development innovation ability and behavior, give employees full authorization, promote employees with higher levels of creativity, at the same time, build good organization environment, and let the employees feel fully perceived organizational support. It improves the intrinsic motivation of individual creativity and work autonomy.

\subsection{Research Conclusion}

As one of the important factors of organization development, employee potential development for enterprise development has a promoting effect, which can improve organizational performance; this effect is influenced by individual factors and environmental factors and shows the differences. If enterprises want to improve the individual creativity, they must be from the individual characteristics and organizational environment improvement, to better motivate employees potential. Haidilao is just such an example [19]. Although many people think that haidilao is not easy to learn, but think carefully, haidilao tells the extraordi- 
nary story of a group of ordinary people. If we can seriously feel and analyze, and fully tap the potential of employees, then we can also find the value logic and path to make ordinary people become extraordinary. When we see the key, everyone can achieve great things. Isn't this kind of value mining for ordinary people more charming than simply expressing "cold" performance figures? This is the root of high-performance enterprises.

\section{Conflicts of Interest}

The authors declare no conflicts of interest regarding the publication of this paper.

\section{References}

[1] Amabile, T.M. (1996) Creativity in Context: Update to The social psychology of creativity. Westview Press, Boulder, CO.

[2] Liu, Y. and Shi, J.T. (2010) Study on the Influence Process of Organizational Innovation Climate on Employees' Innovative Behavior-Based on the Analysis of the Mediating Effect of Psychological Authorization. China Soft Science, No. 3, 133-144.

[3] Chang, S., Jia, L., Takeuchi, R., et al. (2014) Do High-Commitment Work Systems Affect Creativity? A Multilevel Combinational Approach to Employee Creativity. Journal of Applied Psychology, 99, 665-680. https://doi.org/10.1037/a0035679

[4] Chiang, Y.-H., Hsu, C.-C. and Shih, H.-A. (2015) Experienced High Performance Work System, Extroversion Personality, and Creativity Performance. Asia Pacific Journal of Management, 32, 531-549. https://doi.org/10.1007/s10490-014-9403-y

[5] Zhou, J. and George, J.M. (2001) When Job Dissatisfaction Leads to Creativity: Encouraging the Expression of Voice. Academy of Management Journal, 44, 682-696.

[6] Plucker, J.A., Beghetto, R.A. and Dow, G.T. (2004) Why Isn't Creativity More Important to Educational Psychologists? Potentials, Pitfalls, and Future Directions in Creativity Research. Educational Psychologist, 39, 83-96. https://doi.org/10.1207/s15326985ep3902_1

[7] Zhou, J. and Hoever, I.J. (2014) Research on Workplace Creativity: A Review and Redirection. Annual Review of Organizational Psychology and Organizational Behavior, 1, 333-359. https://doi.org/10.1146/annurev-orgpsych-031413-091226

[8] Yuan, F. and Woodman, R.W. (2010) Innovative Behavior in the Workplace: The Role of Performance and Image Outcome Expectations. Academy of Management Journal, 53, 323-342. https://doi.org/10.5465/amj.2010.49388995

[9] Kozlowski, S.W.J. (1987) Technological Innovation and Strategic HRM: Facing the Challenge of Change. Human Resource Planning, 10, page.

[10] Amabile, M.T. (1993) Motivational Synergy: Toward New Conceptualizations of Intrinsic and Extrinsic Motivation in the Workplace. Human Resource Management Review, 3, 185-201. https://doi.org/10.1016/1053-4822(93)90012-S

[11] Shalley, C.E. and Gilson, L.L. (2004) What Leaders Need to Know: A Review of Social and Contextual Factors That Can Foster or Hinder Creativity and Productivity. The Leadership Quarterly, 15, 33-53. https://doi.org/10.1016/j.leaqua.2003.12.004

[12] Woodman, R.W., Sawyer, J.E. and Griffin, W.R. (1993) Toward a Theory of Organizational Creativity. Academy of Management Review, 18, 293-321.

https://doi.org/10.5465/amr.1993.3997517 
[13] Ma Prieto, I. and Pérez-Santana, M.P. (2016) Managing Innovative Work Behavior: The Role of Human Resource Practices. Personnel Review, 43, 184-208. https://doi.org/10.1108/PR-11-2012-0199

[14] Chen, C. (2016) Achievement Sharing Era of "Water Sample Organization". Chinese and Foreign Management, No. 3, 25.

[15] Chen, C. and Zhao, H.R. (2018) Symbiosis: The Evolution Path of Future Enterprise Organization. CITIC Publishing Group, Beijing.

[16] Huang, T., Liang, J. and Pan, Y. (2009) Management Wisdom of "Haidilao". Business Review, No. 4, 82-91.

[17] Li, J., Lu, L. and Liu, J. (2015) Human Resource Management Practice and Employee Creativity: A Review and Management Enlightenment. China Human Resource Development, 19, 39.

[18] Jiang, H. (2005) On the Excavation of Employees' Potential from the Realization of Self-Value. Abstract of Management Science, No. 6, 18-20.

[19] Wang, Y.P. and Zhao, W.L. (2018) Research on the Influence of Personality Traits on Employee Creativity. Soft Science, 32, 93-96. 